\title{
Factors affecting attitude toward safe sex and reproductive health among Shiraz City youth Farah Asna-Ashari*
}

\author{
Address: Ministry of Education, Tehran Suburb Education Organization, Tehran, Iran \\ Email: Farah Asna-Ashari* - farahesnaashari@yahoo.com \\ * Corresponding author
}

from 2006 International Meeting of The Institute of Human Virology

Baltimore, USA. 17-21 November, 2006

Published: 21 December 2006

Retrovirology 2006, 3(Suppl I):P3 doi:I0.I I86/I 742-4690-3-SI-P3

(C) 2006 Asna-Ashari; licensee BioMed Central Ltd.

Youth are the most vulnerable to reproductive and sex issues than the others. Many young people face the risk of Sexually Transmitted Infections (STIs), HIV, physical abuse and sexual violence, female genital mutilation, unintended pregnancy, and emotional, cultural and social problems related to their sexual and reproductive health.

Iranian youth like many other counterparts throughout the world encounter social, cultural and economic barriers to the information and health services they need to protect themselves against sexual and reproductive diseases.

The purpose of this study was to examine the relationship between some demographic, socio-economic, and cultural factors affecting the attitude toward safe sex and reproductive health among Shiraz city youth. A cross-sectional quantitative survey was conducted in Shiraz city with a final sample of 384 youth in fall 2004. The data collection was done by use of a self-administered questionnaire. The data was coded and analyzed by the use of SPSS 11.5. Results are presented in both descriptive and inferential statistic tables.

The multivariate analysis showed that six of fourteen studied independent variables have effect on youth attitude toward safe sex and reproductive health in Shiraz city; interpersonal communications, father's education, access to modern applicants and facilities, awareness about safe sex and reproductive health, non-printed mass media habits, and printed mass media habits. 